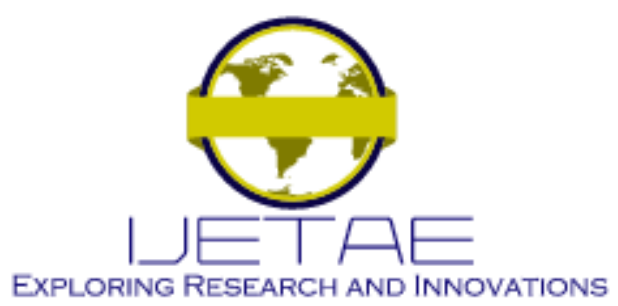

International Journal of Emerging Technology and Advanced Engineering

Website: www.ijetae.com (E-ISSN 2250-2459, Scopus Indexed, ISO 9001:2008 Certified Journal, Volume 12, Issue 02, February 2022)

\title{
Comparative Evaluation of Sequential and Parallel Methods for Identifying Measurements of Nearby Objects
}

\author{
Hennadii Khudov ${ }^{1}$, Serhii Lohachov ${ }^{2}$, Dmytro Karlov ${ }^{3}$, Yuriy Solomonenko ${ }^{4}$, Serhii Sukonko ${ }^{5}$, Sergii Gakhovych ${ }^{6}$, \\ Borys Holovko ${ }^{7}$ \\ 1,2,3,4,7Ivan Kozhedub Kharkiv National Air Force University, Ukraine, Kharkiv, 61023 \\ ${ }^{5}$ National Academy of the National Guard of Ukraine, Ukraine, Kharkiv, 61001 \\ ${ }^{6}$ Military Institute of Taras Shevchenko Kyiv National University, Ukraine, Kyiv, 03189
}

\begin{abstract}
The paper proposes the comparative evaluation of sequential and parallel methods for identifying measurements of nearby objects. The problem statement is choosing the method for identifying measurements of nearby objects. The decision rule for identifying the results of radio engineering measurements of the coordinates of objects is obtained. The decision rules for identifying objects by sequential and parallel methods under various conditions are obtained. The cases of absence and presence of false marks from nearby objects are considered. The task of choosing serial or parallel methods for identifying measurements from nearby objects was set. The comparative evaluation of serial and parallel measurement identification methods is provided. As an indicator of the effectiveness of the methods, we chosen the probability of identification error. We estimated the probability of identification error depending on the relative average distance between objects in the absence of false measurements and in their presence. It is determined that the probability of an identification error when using the parallel identification method is less than when using the sequential identification method. This gain increases as the average relative distance between objects decreases. Based on the analysis of methods for identifying measurement results, it was found that the most appropriate identification method is a parallel method for identifying measurement results. The efficiency of the method increases with decreasing relative average distance between objects.
\end{abstract}

Keywords - evaluation, sequential method, parallel Method, identification, measurement, nearby object, hypothesis

\section{INTRODUCTION}

The examples of situations where it is necessary to identify measurements of nearby objects provide in [1-2]. This is, for example, the separation of two airborne objects (Fig. 1 [1-2]).

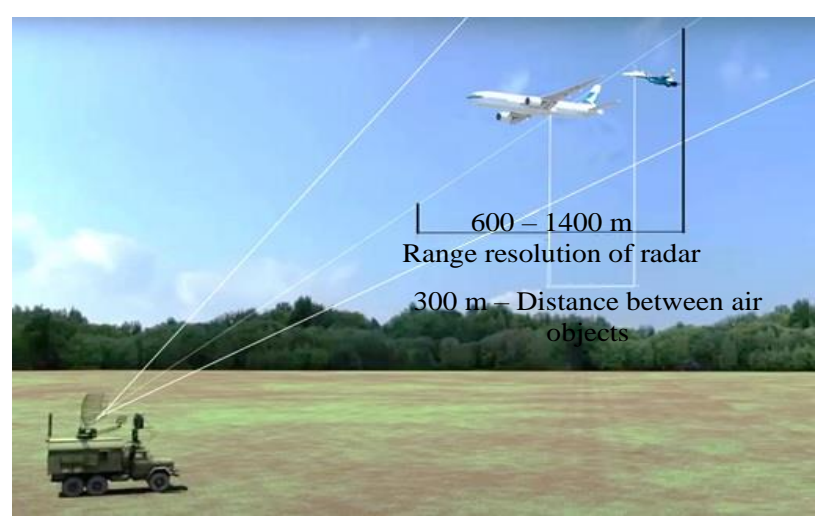

Fig. 1 The example of separation of two nearby air objects [1-2]

At present, the problem of identifying measurements from nearby objects is relevant for monitoring outer space also [3]. For example, China said that the Tiangong Orbital Station had to take urgent measures to avoid collisions with Starlink satellites [4]. The Chinese side calls on the US to "answer for this." Beijing has asked the UN to remind the United States of adherence to the treaty that governs the use of outer space. This happened after the Starlink satellites, which are launched into space by Elon Musk's Space-X, nearly collided with the orbiting Tiangong space station. According to the Chinese side, such "nearcollision" incidents have occurred twice in 2021 [4]. Already shortly after the first launch of Elon Musk's satellites in May 2019, astronomers noted an increased brightness of these satellites [5-6]. Astronomers have expressed concern about possible obstacles that will complicate the observation of the night sky (Fig. 2 [5], Fig. $3[6])$. 


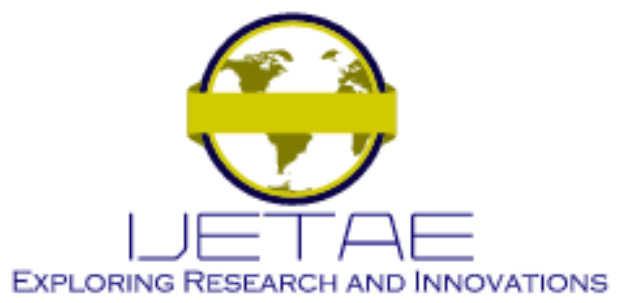

International Journal of Emerging Technology and Advanced Engineering

Website: www.ijetae.com (E-ISSN 2250-2459, Scopus Indexed, ISO 9001:2008 Certified Journal, Volume 12, Issue 02, February 2022)

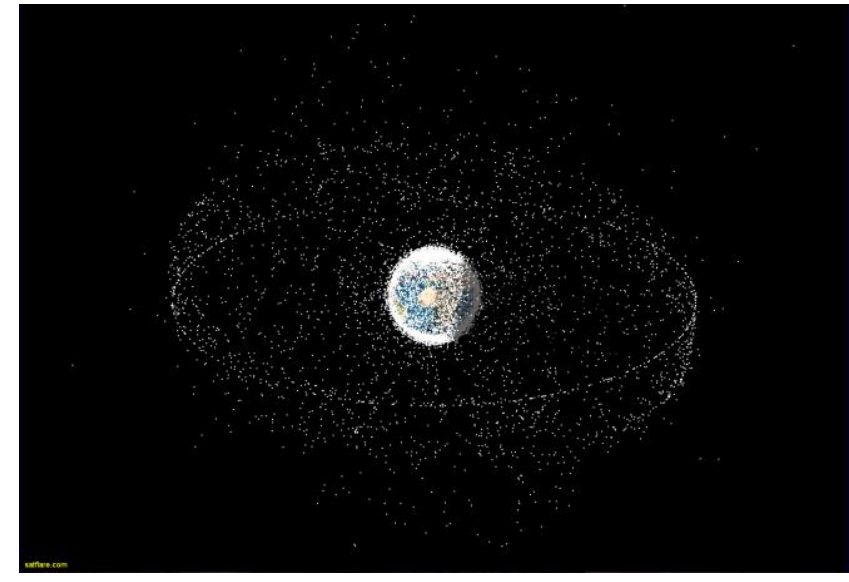

Fig. 2 Satellites in outer space [5]

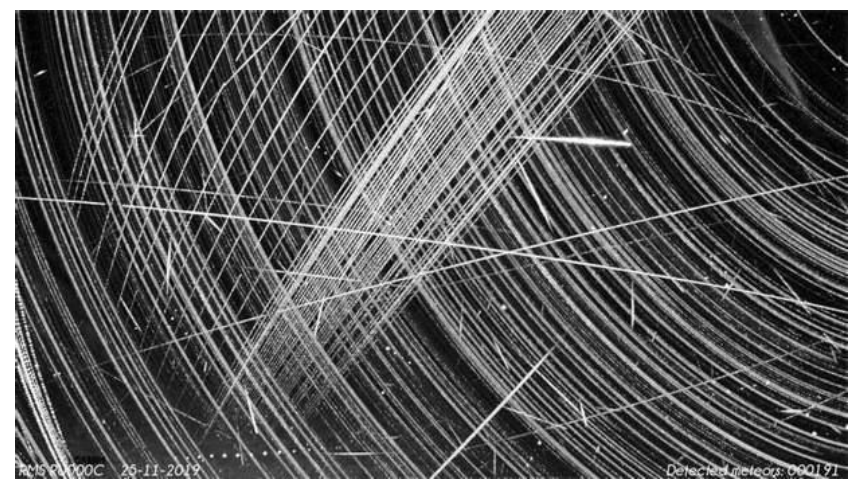

Fig. 3 Elon Musk's satellites illuminate observatory research cameras [6]

Separation of nearby objects is also relevant for observations of asteroids and comets. A huge number of comets and asteroids move in the solar system [7]. Most of them (more than 98\%) are concentrated in the main asteroid belt and the Kuiper belt (Fig. 4 [7]). Periodically, some objects in these regions, as a result of collisions with their neighbors and under the influence of gravity of larger objects, leave their usual orbits and can be directed towards the Earth [7-8].

There are also many asteroids orbiting the Sun closer than the main belt. Those of them that approach the Earth, depending on the parameters of the orbit, are assigned to one of the following four groups (traditionally called by the name of the first open representative): Cupids; Apollos, Athyra, Atons [8].

A schematic example of the location of asteroids is shown in Fig. 5 [7].

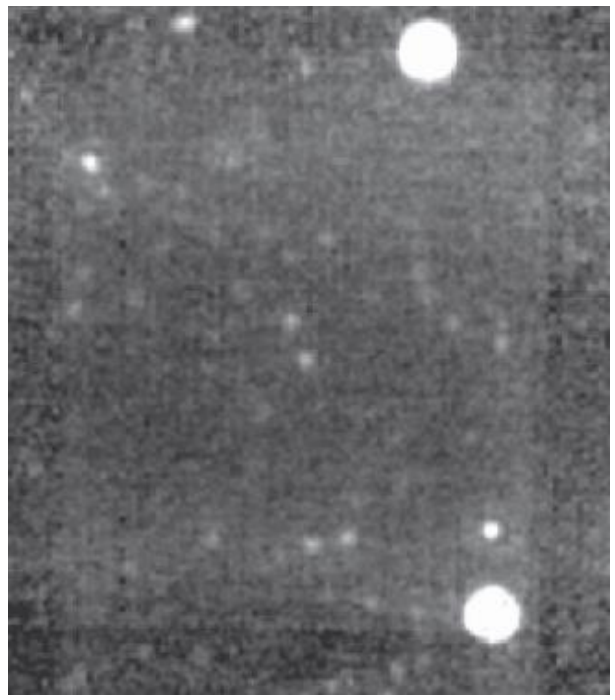

Fig. 4 Asteroids in the Kuiper belt [7]
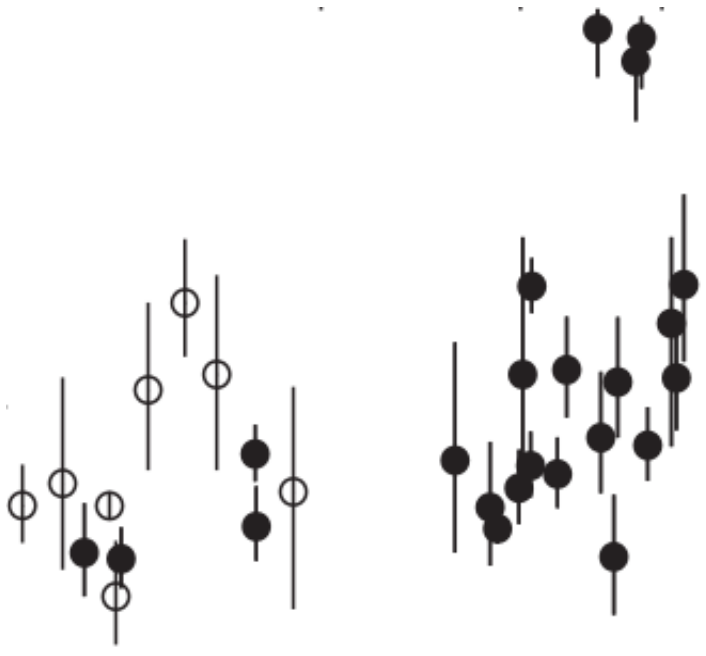

78

Fig. 5 A schematic example of the location of asteroids [7]

Thus, the development, research and comparative assessment of methods for identifying measurements of closely spaced objects are relevant.

\section{LITERATURE REVIEW AND PROBLEM STATEMENT}

The paper [9] proposes results of classification problem by Bayesian method. The paper present the classification method and Bayes error. 


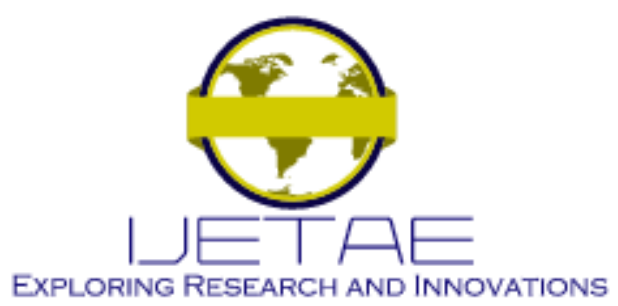

International Journal of Emerging Technology and Advanced Engineering Website: www.ijetae.com (E-ISSN 2250-2459, Scopus Indexed, ISO 9001:2008 Certified Journal, Volume 12, Issue 02, February 2022)

The determination for Bayes error for one measurement and multi measurements is considered. An algorithm to determine the prior probability is proposed. This algorithm can make to reduce Bayes error. The algorithm has been used by the MATLAB. But the results [9] are applied in medicine, biology and economics only.

The paper [10] discusses a ranking method using the simplest Bayesian classifier for a variable number of features using the theory of fractals. The theory of fractals allows you to obtain additional information in the classifier - the characteristic of self-similarity. For this, the simplest Bayesian classifier is modified and the Hurst exponent of the data is determined. The Hurst exponent is associated with the traditional fractal dimension. The disadvantage [10] is a significant computing resource and operating time.

The paper [11] proposes the simplest non-Bayesian approach. The likelihood coefficient of belonging to the objects' trajectories is calculated. To continue the trajectory of object, one of them is selected. The likelihood coefficient takes the maximum value.

In [12] a method is developed for identifying measurements when processing signals from dual-band radar systems. The achieved technical result is an increase in the speed and accuracy of identification of measurements coming from dual-band radar systems. The essence of the proposed method is that in each $\mathrm{j}$-th range for the obtained group of measurements for all tracked targets, residuals are formed. These residuals represent the difference between the obtained measurements and the predicted phase coordinates of the tracked target. Further, for all followed trajectories, quality functionals are formed. The decision on whether the obtained measurements belong to one or another of the tracked targets is made according to the minimum value of the functionals, determined in the process of enumerating them. However, method [12] is ineffective in identifying measurements from nearby objects.

In [13] a method for identifying aircraft at all possible ranges and angles of location is proposed. The achieved technical result is an increase in the reliability of automatic identification of air objects in the quasi-optical region of reflection of radio waves.
This takes into account a stricter mutual correspondence between real and reference long-range portraits. It also takes into account additional information about the amplitudes of impulse responses in the structure of the long-range portrait. The specified technical result is achieved by the fact that the identification of an airborne object takes into account not only the coincidence of the mutual arrangement of the scattering centers of the surface of the airborne object along the line of sight, but also their amplitude. At the same time, higher identification characteristics are provided. The method [13] is ineffective in identifying measurements from nearby objects.

The paper [14] proposes the branching method. The method proposes the forks of the trajectory. The likelihood function is calculated for each trajectory's fork. The main disadvantage of the [14] is the significant computational complexity.

The papers [15-16] propose a priori and a posteriori Bayesian classifiers. The basic properties of Bayesian classifiers: optimal, no other method can outperform it on average; can classify by any element of the linear shell hypothesis. But you need to sort out all the hypotheses, and there are a lot of all hypotheses.

LeRoy T.E. [17] proposes the posterior method of classification. It is notes that with the large distances between objects, a low probability of the presence of false objects, the methods of a priori and a posteriori Bayesian data classification give the same results. The disadvantage of [17] is their complexity. It linearly depends on the number of objects and on the total number of objects.

The paper [18] proposes a quasi-optimal Bayesian method. It is a method with probabilistic data identification. The disadvantage of this method is the complexity of method.

The paper [19] proposes a tracking method based on a multi-hypothetical data identification model. The paper [20] proposes a tracking method based on the model of joint probabilistic data identification. The disadvantages of methods [19-20] are the high labor intensity. It is possible due to the formation and testing of a huge number of hypotheses. It makes these methods difficult to implement. 


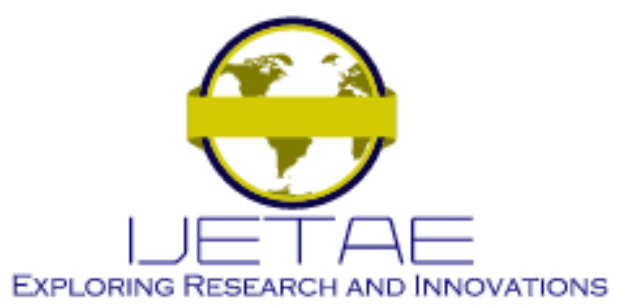

International Journal of Emerging Technology and Advanced Engineering

Website: www.ijetae.com (E-ISSN 2250-2459, Scopus Indexed, ISO 9001:2008 Certified Journal, Volume 12, Issue 02, February 2022)

\section{MATERIALS AND RESEARCH MethodS}

3.1 The decision rule for identifying the results of radio engineering measurements of the coordinates of objects in general form

When solving the problem of synthesizing the decisive rule for the identification of radio-technical measurements of the coordinates of objects, we will assume that there are two objects in the observation zone of the observation radio-technical means. The parameters of the movement of objects are set and obey the normal laws $N_{0}\left(\bar{m}_{0}, K_{0}\right), N_{1}\left(\bar{m}_{1}, K_{1}\right) . \quad \bar{m}_{i}$ is the estimates of the coordinates of objects, $K_{0}, K_{1}$ are the correlation matrices of errors in determining the coordinates of objects.

Let, as a result of the operation of the radio-technical means, one vector of radio-technical measurements $\bar{x}$ of coordinates of the object is formed. In this case, the full group of hypotheses about the belonging of the measurement to one of the objects can be formulated as follows [21-22]:

$H_{0}$ is the vector of radio engineering measurements was obtained when observing the first object;

$H_{l}$ is the vector of radio engineering measurements obtained by observing the second object.

Under the condition of the truth of hypotheses $H_{0}$ and $H_{I}$ of the probability density of the distribution of the parameters of the vector of radio engineering measurements, the $\bar{x}$ coordinates of the object will look as follows [22-23]:

$$
\begin{aligned}
& P_{0}\left(\bar{x} / H_{0}\right)=\frac{1}{(\sqrt{2 \pi})^{n} \sqrt{\operatorname{det}\left(K_{0}\right)}} x \\
& x \exp \left\{-\frac{1}{2}\left(\bar{x}-\bar{m}_{0}\right)^{T} \cdot K_{0}^{-1} \cdot\left(\bar{x}-\bar{m}_{0}\right)\right\} \\
& P_{0}\left(\bar{x} / H_{1}\right)=\frac{1}{(\sqrt{2 \pi})^{n} \sqrt{\operatorname{det}\left(K_{1}\right)}} x \\
& x \exp \left\{-\frac{1}{2}\left(\bar{x}-\bar{m}_{1}\right)^{T} \cdot K_{1}^{-1} \cdot\left(\bar{x}-\bar{m}_{1}\right)\right\}
\end{aligned}
$$

where $\operatorname{det}\left(K_{0}\right)$ and $\operatorname{det}\left(K_{1}\right)$ are the determinants of correlation matrices of coordinates determination errors; $n$ is the dimension of the vector $\bar{x}$.
In accordance with the maximum likelihood method [2223], the decisive rule for sequential identification of radio engineering measurements in the absence of false measurements can be represented as (3):

$\ln \frac{P_{1}\left(\bar{x} / H_{1}\right)}{P_{0}\left(\bar{x} / H_{0}\right)} \stackrel{\substack{H_{1} \\ H_{0}}}{>} 0$.

3.2 The decision rules for identifying objects by sequential and parallel methods in the absence of false measurements

When using a sequential identification method based on the optimal Bayesian approach to solving the problem of identifying new marks, the decision rule for identifying the results of radio engineering measurements can be obtained by substituting (1) and (2) in (3). As a result of the indicated substitution, we obtain (4):

$$
\begin{aligned}
& \left(\bar{x}-\bar{m}_{0}\right)^{T} K_{0}^{-1}\left(\bar{x}-\bar{m}_{0}\right)_{<}^{H_{1}}\left(\bar{x}-\bar{m}_{1}\right)^{T} K_{1}^{-1}\left(\bar{x}-\bar{m}_{1}\right)- \\
& -\ln \frac{\operatorname{det}\left(K_{0}\right)}{\operatorname{det}\left(K_{1}\right)}
\end{aligned}
$$

As a method based on the optimal Bayesian approach to solving the problem of identifying new marks, we will consider a method when at each step of observation the posterior probabilities of possible options for constructing a trajectory are calculated from the data of all completed observation cycles, up to the $n$-th one. The variant with the maximum posterior probability of realization is chosen as the worker.

The number of hypotheses can be reduced by discarding that part of them that have a small posterior probability. Then you can combine hypotheses for which the same measurements are included in the last $\mathrm{n}$ measures. The result is a quasi-optimal Bayesian algorithm suitable for practical implementation, this algorithm is known as an algorithm with probabilistic data identification. The advantage of this method in comparison with the tracking algorithm with identification by the minimum distance of the mark from the center of the gate is the fact that with the deterioration of the noise environment (an increase in the average number of false marks in the gate), the number of dropped false trajectories significantly increases. However, if there are 4 marks in the strobe, the complexity of the algorithm with probabilistic data identification increases by about 2 times. 


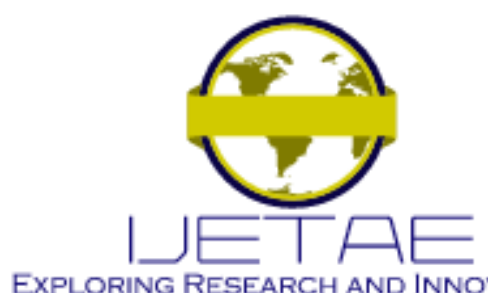

EXPLORING RESEARCH AND INNOVATIONS

\section{International Journal of Emerging Technology and Advanced Engineering}

\section{Website: www.ijetae.com (E-ISSN 2250-2459, Scopus Indexed, ISO 9001:2008 Certified Journal, Volume 12, Issue 02, February 2022)}

The methods for identifying radar information described above belong to the class of strobe methods with sequential data arrival and are used mainly in solving problems of tracking single targets in interference. At the same time, when calculating the hypotheses of the origin of the marks that fell into the strobe of the tracked trajectories, the possibility of their belonging to another tracked object is not taken into account. This other facility is located very close to the first one. We are talking about the joint tracking of several targets moving at short distances from each other. This occurs when crossing their trajectories or when flying in a group. In these cases, the tracking strobes overlap with each other, and the resulting markings can be correlated with multiple trajectories.

The approach used in the synthesis of the decision rule in the case of parallel identification of radio engineering measurements of $\bar{x}_{1}$ and $\bar{x}_{2}$ coordinates of objects in the absence of false measurements is similar to the previous one. Let, as a result of the operation of the radio-technical means, two vectors of radio-technical measurements and coordinates of different objects are formed. To synthesize the decisive rule for identifying measurements of the coordinates of two objects, we formulate a complete group of hypotheses [21-22]:

$H_{0}$ is the first vector of radio engineering measurements was obtained when observing the first object, the second vector of radio engineering measurements was obtained when observing the second object;

$H_{l}$ is the first vector of radio engineering measurements was obtained when observing the second object, the second vector of radio engineering measurements was obtained when observing the first object.

The joint distribution densities of the measurement parameters at the point with coordinates $\bar{x}_{1}$ and $\bar{x}_{2}$, provided that hypotheses $H_{0}$ and $H_{l}$ are true and the measurements are independent of each other, will look as follows [24-25]:

$$
\begin{aligned}
& P_{0}\left(\bar{x}_{1}, \bar{x}_{2} / H_{0}\right)=\frac{1}{(\sqrt{2 \pi})^{n} \sqrt{\operatorname{det}\left(K_{0}\right)}} \times \\
& \times \exp \left\{-\frac{1}{2}\left(\bar{x}_{1}-\bar{m}_{0}\right)^{T} K_{0}^{-1}\left(\bar{x}_{1}-\bar{m}_{0}\right)\right\} \times \\
& \times \frac{1}{(\sqrt{2 \pi})^{n} \sqrt{\operatorname{det}\left(K_{1}\right)}} \exp \left\{-\frac{1}{2}\left(\bar{x}_{2}-\bar{m}_{1}\right)^{T} K_{1}^{-1}\left(\bar{x}_{2}-\bar{m}_{1}\right)\right\},
\end{aligned}
$$

$$
\begin{aligned}
& P_{1}\left(\bar{x}_{1}, \bar{x}_{2} / H_{1}\right)=\frac{1}{(\sqrt{2 \pi})^{n} \sqrt{\operatorname{det}\left(K_{1}\right)}} \times \\
& \times \exp \left\{-\frac{1}{2}\left(\bar{x}_{1}-\bar{m}_{1}\right)^{T} K_{1}^{-1}\left(\bar{x}_{1}-\bar{m}_{1}\right)\right\} \times \\
& \times \frac{1}{(\sqrt{2 \pi})^{n} \sqrt{\operatorname{det}\left(K_{0}\right)}} \exp \left\{-\frac{1}{2}\left(\bar{x}_{2}-\bar{m}_{0}\right)^{T} K_{0}^{-1}\left(\bar{x}_{2}-\bar{m}_{0}\right)\right\} .
\end{aligned}
$$

In this case, the expression for the decision rule of identification by the parallel method in the absence of false measurements has the form (7) [24-25]:

$$
\begin{aligned}
& \left(\bar{x}_{1}-\bar{m}_{0}\right)^{T} K_{0}^{-1}\left(\bar{x}_{1}-\bar{m}_{0}\right)+\left(\bar{x}_{2}-\bar{m}_{1}\right)^{T} K_{1}^{-1}\left(\bar{x}_{2}-\bar{m}_{1}\right)_{<}^{H_{H_{0}}}>{ }^{H_{1}}(7) \\
& \stackrel{H_{1}}{>}\left(\bar{x}_{1}-\bar{m}_{1}\right)^{T} K_{1}^{-1}\left(\bar{x}_{1}-\bar{m}_{1}\right)+\left(\bar{x}_{2}-\bar{m}_{0}\right)^{T} K_{0}^{-1}\left(\bar{x}_{2}-\bar{m}_{0}\right) .
\end{aligned}
$$

Expressions (4) and (7) define the decision rules for identifying objects by sequential and parallel methods in the absence of false measurements.

3.3 The decision rule for identifying the results of radio engineering measurements when using sequential identification methods in the presence of false measurements

To synthesize the decision rule for sequential identification in the presence of false measurements, we formulate the problem as follows. Suppose that as a result of the operation of the radio technical means on two objects, the estimates of the motion parameters of which are subject to the normal laws $N_{0}\left(\bar{m}_{0}, K_{0}\right), N_{1}\left(\bar{m}_{1}, K_{1}\right)$, one vector of radio engineering measurements $\bar{x}$ was formed.

In this case, there is a possibility of obtaining false measurements from an object, the coordinates of which are distributed according to the uniform law $P_{e r r}(\bar{x})=p_{0}$. It is necessary to synthesize the decisive rule for identifying vectors of radio engineering measurements for two objects in the presence of false objects.

Let us form a complete group of hypotheses:

$H_{0}$ is the vector of radio engineering measurements was obtained when observing the first object; 


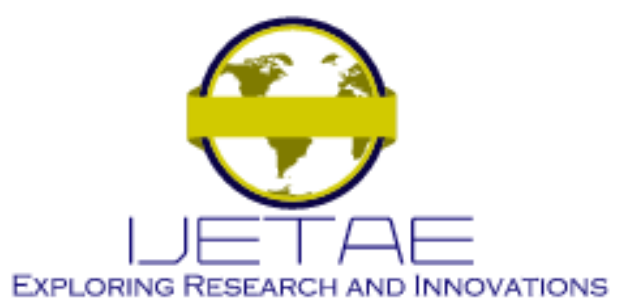

International Journal of Emerging Technology and Advanced Engineering

Website: www.ijetae.com (E-ISSN 2250-2459, Scopus Indexed, ISO 9001:2008 Certified Journal, Volume 12, Issue 02, February 2022)

$H_{l}$ is the vector of radio engineering measurements was obtained when observing the second object;

$\mathrm{H}_{2}$ is the vector of radio engineering measurements is false (i.e., it is obtained neither from the first nor from the second object).

The distribution densities of the measurement parameters at the point with coordinates $\bar{x}$, provided that hypotheses $H_{0}$ and $H_{l}$ are true, are determined by expressions (1) and (2), respectively. Then the decision rule for sequential identification in the presence of a false measurement will be written as follows (8):

$j=\max \left\{P_{0}\left(\bar{x} / H_{0}\right), P_{1}\left(\bar{x} / H_{1}\right), P_{f}(\bar{x})\right\}$,

where $j=\overline{0,2}, j$ is the hypothesis number.

3.4 The decision rule for identifying the results of radio engineering measurements when using parallel identification methods in the presence of false measurements

For the synthesis of the decision rule by the method of parallel identification of radio engineering measurements in the presence of false ones, we formulate the problem as follows. Suppose that, as a result of the operation of the radio technical means on two objects, the estimates of the motion parameters of which are subject to the normal laws $N_{0}\left(\bar{m}_{0}, K_{0}\right), N_{1}\left(\bar{m}_{1}, K_{1}\right)$, two vectors of radio engineering measurements $\bar{x}_{1}$ and $\bar{x}_{2}$. There is a probability of obtaining false measurements, the coordinates of which are distributed according to the uniform law $P_{\text {err }}(\bar{x})=p_{0}$.

It is necessary to synthesize the decisive identification rule vectors of radio engineering measurements for two objects in the presence of false objects. 25]:

Let us formulate the complete group of hypotheses [24-

$H_{0}$ is the measurements taken are false (received not from true objects but from background objects);

$H_{l}$ is the first vector of radio engineering measurements was obtained while observing the first object, the second is false;

$\mathrm{H}_{2}$ is the first vector of radio engineering measurements was obtained while observing the second object, the second is false;

$\mathrm{H}_{3}$ is the first vector of radio engineering measurements is false, the second was obtained while observing the first object;
$\mathrm{H}_{4}$ is the first vector of radio engineering measurements is false, the second was obtained while observing the second object;

$\mathrm{H}_{5}$ is the first vector of radio engineering measurements was obtained when observing the first object, the second vector of radio engineering measurements was obtained when observing the second object;

$H_{6}$ is the first vector of radio engineering measurements was obtained when observing the second object, the second vector of radio engineering measurements was obtained when observing the first object.

The joint distribution densities of the measurement parameters at a point with coordinates $\bar{x}_{1}$ and $\bar{x}_{2}$, provided that hypotheses $H_{5}$ and $H_{6}$ are true and the measurements are independent of each other, are determined from (5) and (6), respectively. Similar expressions for hypotheses $H_{1}$ $\mathrm{H}_{5}$ are obvious.

Then the decision rule when using the parallel identification method in the presence of false measurements will look like formula (9):

$$
j=\max \left\{P_{j}\left(\bar{x} / H_{j}\right)\right\},
$$

where $j=\overline{0,6}$.

In general, the decision rule when using the parallel identification method in the presence of false measurements when accompanying $Q$ objects and $N$ hypotheses of joint identification of objects and vectors of radio engineering measurements obtained in this case will take the form (10):

$$
j=\max \left\{P_{j}\left(\bar{x} / H_{j}\right)\right\},
$$

where $j=\overline{O, N}$.

\subsection{The comparative evaluation of serial and parallel measurement identification methods}

To substantiate the choice of a method for identifying measurement results, we will carry out a comparative assessment of sequential and parallel methods for identifying measurement results. As an indicator of the effectiveness of the methods, we will choose the probability of identification error [24-25].

The probability of an identification error can be determined from the (11) 


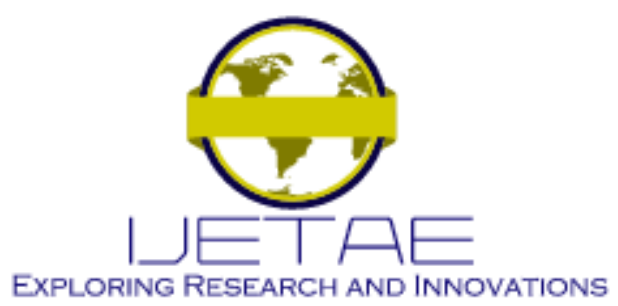

International Journal of Emerging Technology and Advanced Engineering

Website: www.ijetae.com (E-ISSN 2250-2459, Scopus Indexed, ISO 9001:2008 Certified Journal, Volume 12, Issue 02, February 2022)

$$
P_{e r r}=\frac{N_{e r r}}{N_{m e s}},
$$

where $\mathrm{N}_{\text {err }}$ is the number of measurements that were incorrectly identified; $\mathrm{N}_{\text {mes }}$ is the total number of measurements.

We will estimate the probability of identification error (11) depending on the relative average distance between objects in the absence of false measurements and in their presence. The relative average distance between objects is calculated according to (12):

$$
R_{r e l_{i}}=\sqrt{\left(\bar{m}_{x_{i}}-\bar{m}_{x_{j}}\right)^{T} \times 2 \frac{K_{i} \cdot K_{j}}{K_{i}+K_{j}} \times\left(\bar{m}_{x_{i}}-\bar{m}_{x_{j}}\right)} .
$$

Fig. 6 and Fig. 7 show the dependence of the probability of an identification error (expression (11)) on the relative average distance between objects (expression (12)) in the absence of false measurements and in their presence, respectively.

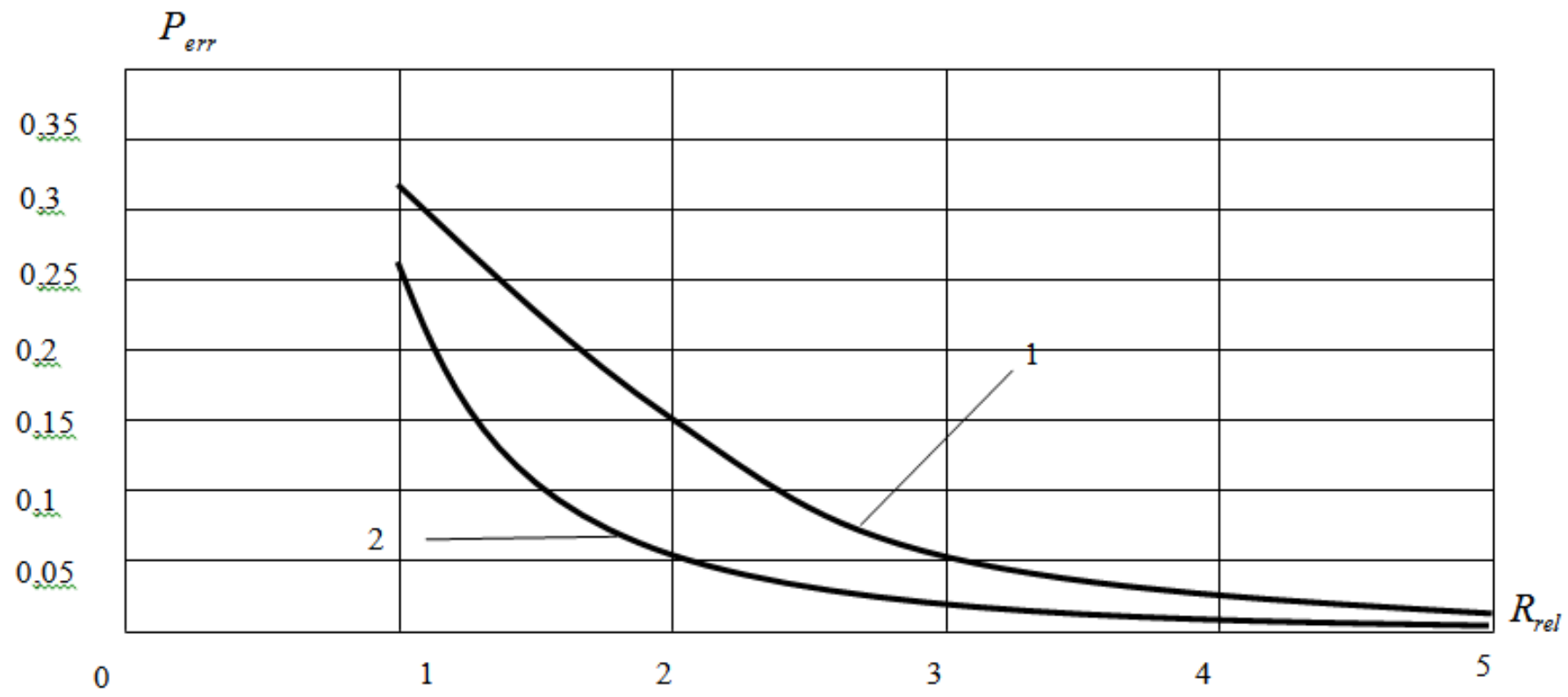

Fig. 6 The dependence of identification errors on the relative average distance between objects for sequential (1) and parallel (2) identification in the absence of false measurements 


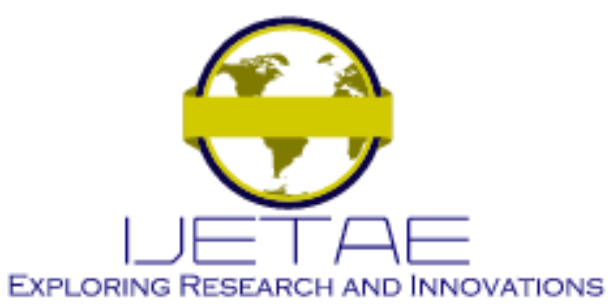

International Journal of Emerging Technology and Advanced Engineering Website: www.ijetae.com (E-ISSN 2250-2459, Scopus Indexed, ISO 9001:2008 Certified Journal, Volume 12, Issue 02, February 2022)

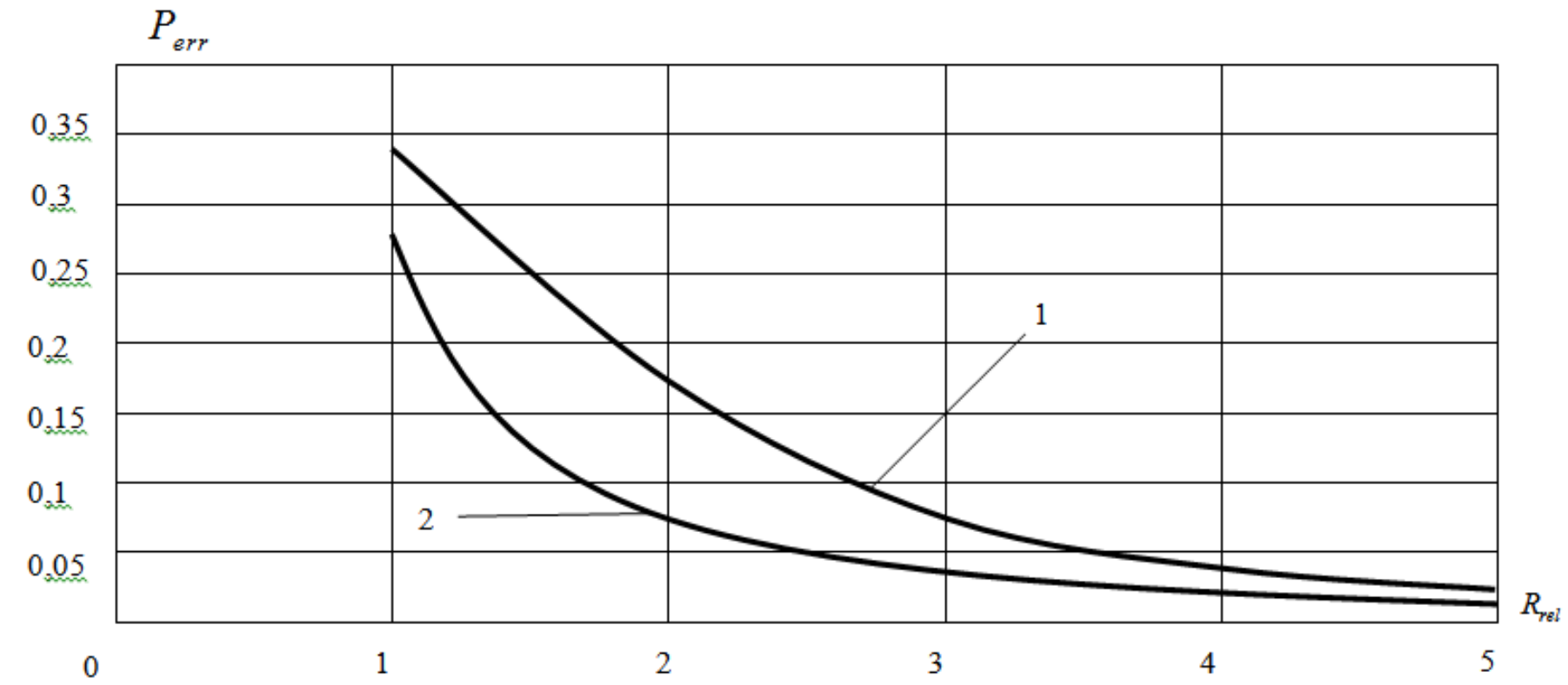

Fig. 7 The dependence of identification errors on the relative average distance between objects for sequential (1) and parallel (2) identification in the presence of false measurements

The graphs (Fig. 6, Fig. 7) show that the probability of an identification error when using the parallel identification method is less than when using the sequential identification method. This gain increases as the average relative distance between objects decreases. Based on the analysis of methods for identifying measurement results, it was found that the most appropriate identification method is a parallel method for identifying measurement results. The efficiency of the method increases with decreasing relative average distance between objects.

\section{CONCLUSIONS}

Thus, the paper proposes the comparative evaluation of sequential and parallel methods for identifying measurements of nearby objects. The decisive rule for identifying the results of radio engineering measurements of the coordinates of objects in general form is obtained. The decisive rules for identifying objects by sequential and parallel methods in the absence of false measurements is obtained. The decisive rule for identifying the results of radio engineering measurements when using sequential identification methods in the presence of false measurements is obtained. The decisive rule for identifying the results of radio engineering measurements when using parallel identification methods in the presence of false measurements is obtained.
The comparative evaluation of serial and parallel measurement identification methods is provided. As an indicator of the effectiveness of the methods, we will choose the probability of identification error. We will estimate the probability of identification error depending on the relative average distance between objects in the absence of false measurements and in their presence. It is determined that the probability of an identification error when using the parallel identification method is less than when using the sequential identification method. This gain increases as the average relative distance between objects decreases. Based on the analysis of methods for identifying measurement results, it was found that the most appropriate identification method is a parallel method for identifying measurement results. The efficiency of the method increases with decreasing relative average distance between objects.

The subjects of further research are:

To improve the method of joint probabilistic identification of radio engineering measurements of coordinates of closely located objects;

To synthesize the optimal decision rule for joint identification of objects and measurements in the presence of background objects 


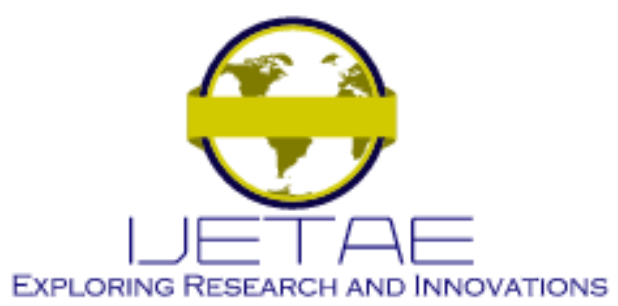

International Journal of Emerging Technology and Advanced Engineering

Website: www.ijetae.com (E-ISSN 2250-2459, Scopus Indexed, ISO 9001:2008 Certified Journal, Volume 12, Issue 02, February 2022)

\section{REFERENCES}

[1] Khudov H., Ruban I., Pievtsov H., Makoveichuk O., Popkov O., Shabanov D., Baranov Y., Solomonenko Y., Kryvosheiev V., Khudov R. The Method for Identification of Radars Measurements of Nearby Objects Tracking. International Journal of Emerging Technology and Advanced Engineering, Vol. 11, Iss. 12, 2021. P. 104-111. DOI: https://doi.org/10.46338/ijetae1221_12.

[2] Khudov H., Diakonov O., Kuchuk N., Maliuha V., Furmanov K., Mylashenko I., Olshevskyi Y., Stetsiv S., Solomonenko Y., Yuzova I. Method for determining coordinates of airborne objects by radars with additional use of ADS-B receivers. Eastern-European Journal of Enterprise Technologies, № 4/9 (112), 2021. P. 54-64. DOI: https://doi.org/10.15587/1729-4061.2021.238407.

[3] Anttonen A., Kiviranta M., Höyhtyä M. Space debris detection over intersatellite communication signals. Acta Astronautica, Vol. 187, 2021. P. 156-166.

[4] Retrieved at: https://www.theguardian.com/science/2021/dec/28/ china-complains-to-un-after-space-station-is-forced-to-move-toavoid-starlink-satellites.

[5] Retrieved at: https://www.starlink.com.

[6] Retrieved at: https://spacenews.com/spacex-working-on-fix-forstarlink-satellites-so-they-dont-disrupt-astronomy/.

[7] Stansberry J., Brown M., Cruikshank D., Spencer J., Trilling D., Margot J. L. Physical Properties of Kuiper Belt and Centaur Objects: Constraints from the Spitzer Space Telescope. Available from: https://www.lpi.usra.edu/books/ssbn2008/7017.pdf.

[8] Retrieved at: https://ru.wikipedia.org/wiki/.

[9] Vovan T. Classifying by Bayesian Method and Some Applications, Bayesian Inference, Javier Prieto Tejedor, IntechOpen, DOI: 10.5772/intechopen.70052. Available from: https://www.intechopen.com/chapters/56503.

[10] Turkanov G.I., Scepin E.V. Bayes classifier for a variable number of features. $2016 . \quad$ Available from: https://www.intechopen.com/chapters/56503.

[11] Fengler A., Haghighatshoar S., Jung P., Caire G. Non-Bayesian Activity Detection, Large-Scale Fading Coefficient Estimation, and Unsourced Random Access With a Massive MIMO Receiver. IEEE Transactions on Information Theory. Vol. 67, Issue 5, 2021. P. 2925 - 2951. DOI: https://doi.org/0.1109/TIT.2021.3065291.

[12] Zak B., Hozyn S. A surface and air object identification set. Zeszyty Naukowe Akademii Marynarki Wojennej. 2015. 200(1):1-1. DOI:10.5604/0860889X.1161263. Available from: https://www.researchgate.net/publication/283201351_A_surface_an d_air_object_identification_set.

[13] Su J. The Practice of States on Air Defense Identification Zones: Geographical Scope, Object of Identification, and Identification Measures. Chinese Journal of International Law. Vol. 18, Iss. 4, 2019, P. 812-835. DOI: https://doi.org/10.1093/chinesejil/jmaa001.

[14] Tu. G., Chen C., Gong Z., Wang Y. A Form-Finding Method for Branching Structures Based on Dynamic Relaxation. Applied Science. № $11.2021 . \quad 7165 . \quad$ DOI: https://doi.org/10.3390/app11157165.
[15] Khudov H., Khizhnyak I., Zots F., Misiyuk G., Serdiuk O. The Bayes Rule of Decision Making in Joint Optimization of Search and Detection of Objects in Technical Systems, International Journal of Emerging Trends in Engineering Research, № 8(1), 2020, P. 7-12. DOI: https://doi.org/10.30534/ijeter/2020/02812020.

[16] Khudov G.V. Features of optimization of two-alternative decisions by joint search and detection of objects. Problemy Upravleniya I Informatiki (Avtomatika), 2003, № 5, P. 51-59.

[17] LeRoy T.E., Hayden B.L., Desmarais J., Menendez M.E., War D. Early Outcome Comparison of the Posterior Approach and the Superior Approach for Primary Total Hip Arthroplasty. Arthroplasty Today. Vol. 6, Iss. 3, 2020, P. 508-512. DOI: https://doi.org/10.1016/j.artd.2020.05.005.

[18] Inoue A., Shintani M. Quasi-Bayesian Model Selection. 2020. Retrieved at: https://www.qeconomics.org/ojs/forth/587/587-3.pdf.

[19] Meinhardt T., Leal-Taixe L., Bergmann P. Tracking without bells and whistles. $2019 . \quad$ Retrieved https://arxiv.org/pdf/1903.05625.pdf

[20] Shaoming He S., Shin H.S., Tsourdos A. Distributed multiple model joint probabilistic data association with Gibbs sampling-aided implementation. Information Fusion. Vol. 64, 2020, P. 20-31. DOI: https://doi.org/10.1016/j.inffus.2020.04.007.

[21] Lishchenko V., Kalimulin T., Khizhnyak I., Khudov H. The method of the organization coordinated work for air surveillance in MIMO radar. (2018). Paper presented at the 2018 International Conference on Information and Telecommunication Technologies and Radio Electronics, UkrMiCo, 2018. Proceeding. DOI: https://doi.org/doi:10.1109/ UkrMiCo43733.2018.9047560.

[22] Khudov, H., Oleksenko, O., Lukianchuk, V., Herasymenko, V., Yaroshenko, Y., Ishchenko, O., Ikaiev, D., Golovchenko O., Volobuiev, A., Drob, Y., Solomonenko, Y., Khizhnyak, I. The Determining the Flight Routes of Unmanned Aerial Vehicles Based on Swarm Methods. International Journal of Emerging Technology and Advanced Engineering. 2021. Vol. 11. Issue 09, P. 23-32. DOI: 10.46338/ijetae0921_03.

[23] Ruban I., Khudov H., Lishchenko V., Pukhovyi O., Popov S., Kolos R., Kravets T., Shamrai N., Solomonenko Y., Yuzova I. (2020). The assessment of detection zones of radars with the additional use of external sources emission. Eastern-European Journal of Enterprise Technologies, 6/9 (108), 6-17. DOI: https://doi.org/10.15587/17294061.2020.216118.

[24] Lishchenko V., Khudov H., Tiutiunnyk V., Kuprii V., Zots F., Misiyuk G. The Method of Increasing the Detection Range of Unmanned Aerial Vehicles In Multiradar Systems Based on Surveillance Radars, in 2019 IEEE 39th International Conference on Electronics and Nanotechnology (ELNANO), 2019. P. 559-562. DOI: https://doi.org/10.1109/ELNANO.2019.8783263.

[25] Lishchenko V., Khudov H., Lisogorsky B., Baranik O., Holovniak D., Serdjuk O. The MIMO System on Based Existing Mechanical Rotation Radars with Wide Surveillance Area, in 2020 IEEE 40th International Conference on Electronics and Nanotechnology (ELNANO), 2020. P. 625-628. DOI: https://doi.org/10.1109/ELNANO.50318.2020.90887463. 